\title{
A constituição social da mente: (re)descobrindo Jerome Bruner e construção de significados
}

\author{
Mônica F. B. Correia \\ Universidade Federal da Paraíba
}

\begin{abstract}
Resumo
Este artigo tem por objetivo analisar como a mente se torna social, à luz das idéias de Bruner e frente às idéias de Valsiner. Bruner entende a mente como criadora de significados e busca compreender a interação através da qual a mente constitui e é constituída pela cultura. Propõe uma psicologia interessada na ação e seu caráter situacional, assim como nas formas em que os seres humanos produzem significados nos contextos culturais. As pessoas, para Bruner, são resultado do processo de produção de significados, realizado com o auxílio dos sistemas simbólicos da cultura. O artigo aborda os temas centrais discutidos pelo autor para fundamentar tais pressupostos. Valsiner aparece como um estudioso contemporâneo e em evidência, cujas premissas reivindicam mudanças, principalmente nas pesquisas em Psicologia do Desenvolvimento, semelhantes àquelas apresentadas por Bruner há 50 anos. Estas discussões tornam-se relevantes nos “espaços da Psicologia”, especialmente aqueles relacionados à pesquisa e à Educação.
\end{abstract}

Palavras-chave: mente; psicologia cultural; produção de significados

\begin{abstract}
The social constitution of the mind: (re)discovering Jerome Bruner and construction of meanings. The aim of this article is to analyse how the mind becomes social regarding Bruner's ideas as well as Valsiner's. Bruner, who considers the mind as meanings creator, seeks at understanding the interaction through which the mind constitutes and is constituted by the environment. Bruner proposes a psychology which is interested in the action, its situational feature as well as the way which human beings produce meanings within cultural contexts. According to the author these people are results from the meanings production process, accomplished with the aid of the environmental symbolic systems. This article will approach the themes once discussed by the author so as to serve as a basis to such assumptions. Valsiner will appear as a contemporary scholar in activity, whose premises claim changes, particularly researches in Development Psychology which are similar to those presented by Bruner 50 years ago. Such discussions have become relevant in the "psychology rooms", mainly those related to research and education.
\end{abstract}

Key word: mind; cultural psychology; meanings production

$\mathrm{J}$ á se passaram algumas décadas do início de uma revolução na Psicologia que enfocava questões relacionadas ao estudo da mente e à sua constituição social. Mas, apesar deste tempo, diferentes significados ainda podem ser atribuídos à expressão “mentes sociais”. E para cada um destes é possível localizar um ponto na história da Psicologia. Houve uma época, por exemplo, tão forte que ainda encontram-se seus resquícios, na qual este slogan foi a bandeira erguida pelos behavioristas. Embora mente não fosse o termo usado ou sequer aprovado por estes, o fato é que procuravam demonstrar a influência do meio ou do social em todos os comportamentos e características humanas.
Esta não é a posição enfocada neste ensaio. Pelo contrário, mente é aqui um conceito bem vindo como central e a influência social será vista em termos de interinfluências, ainda que coloque o papel da cultura como fundante do pensamento, ou seja, um papel central na constituição e funcionamento da mente humana.

Inicialmente, porém, é importante esclarecer como cultura pode ser compreendida neste estudo, uma vez que não há um consenso sobre sua definição (Geertz, 1978; Santos, 1996). Por não haver um consenso, cultura freqüentemente é apresentada com vários sentidos, inclusive com o sentido de sociedade. Para Santos (1996), por exemplo, cultura “... remete 
a todos os aspectos de uma realidade social” (p. 23) e diz respeito "... a tudo aquilo que caracteriza a existência social de um povo ou nação, ou então de grupos no interior de uma sociedade”. (p. 24). Seria, assim, “... modos diferentes de organizar a vida social”. (grifo meu; p. 7). De acordo com os pressupostos de Geertz (1978), podemos interpretar cultura como imbricadas e complexas "teias” de significados que são construídos e compartilhados pelos membros de um dado grupo social.

De maneira geral, então, as discussões que envolvem cultura e, especialmente, as relações entre cultura e cognição, apropriam-se dos termos cultural e social praticamente como sinônimos, considerando-se suas interdependências. Neste sentido, cultura, a despeito das discussões que procuram estabelecer os limites entre o cultural e o social, será considerada aqui como um desdobramento da característica humana de filiar-se, viver em grupo, em sociedade. Da sociedade emerge a cultura ou emergem culturas, que são mais restritas à espécie humana, principalmente quando nos referimos à linguagem. Além deste sentido mais geral, esta análise considerará os sentidos mais específicos propostos tanto por Geertz (1978) como por Bruner (2001), ou seja, cultura como um sistema simbólico.

Jerome Bruner (2001), para quem cultura “... é um conjunto de ferramentas com técnicas e procedimentos para entender seu mundo [do indivíduo] e lidar com ele” (p. 98); ou “... um modo de lidar com os problemas humanos: com as transações humanas de todo o tipo, representadas em símbolos” (p. 99), foi o autor eleito para fundamentar este ensaio e a tese da mente social. Ao analisar o percurso acadêmico-histórico deste autor podemos percebê-lo como um dos mais importantes e respeitados defensores da idéia da mente social, além de participante e propulsor da chamada revolução cognitiva da Psicologia. Falar de sua trajetória significa falar um pouco da trajetória da Psicologia, especialmente da Psicologia Cognitiva.

Bruner, já em meados de 1950, na ocasião professor do Departamento de Relações Sociais em Harvard, formou um grupo que estabeleceu uma versão própria de ciência humana interdisciplinar e que gerou o Centro de Estudos Cognitivos. Desde então, esse pesquisador, atualmente docente em Nova York, profere palestras como convidado em vários estados dos Estados Unidos, assim como em outros países. Bruner foi amigo pessoal de Lúria e trabalhou com reconhecidos estudiosos como Inhelder, Geertz, Olson e outros importantes nomes da Psicologia Cognitiva. Os temas desenvolvidos por ele são expressões de uma busca para melhor compreender a atividade mental. E algumas de suas produções trouxeram "mudanças fundamentais sobre a natureza da mente humana nas décadas que se seguiram desde a revolução cognitiva”. (Bruner, 2001, p. 15)

São inúmeros os estudiosos contemporâneos que citam ou recorrem às idéias de Bruner para fundamentar ou apoiar suas próprias teses relacionadas a esse tema (por exemplo, Bronckart, 1998; Fosnot, 1998; Gould, 1998; Rogoff, 1998; Tomasello, 1999; Vasconcellos \& Valsiner, 1995; Wertsch, 1998; Wertsch, Del Río, \& Alvarez, 1998, entre muitos outros). O evidente respeito de estudiosos, a minha identificação com suas idéias e a forma leve e brilhante da escrita do autor foram alguns dos motivos que levaram à sua eleição.

Jerome Bruner tem uma vasta produção, por isso usá-lo como orientador dos argumentos deste artigo chega a parecer presunção, pois seria praticamente impossível analisar ou resgatar toda a sua obra. Em contrapartida, considero possível e produtivo selecionar algumas das suas idéias, aquelas que parecem ter obtido maiores repercussões ou que pelo menos são mais citadas (inclusive pelo autor), ou seja, as que parecem resumir melhor os eixos do seu trabalho, como a Psicologia Cultural, a narrativa e a construção de significados. Neste sentido, o presente estudo se baseou em quatro livros de Jerome Bruner, principalmente nos mais recentes, além de incluir alguns dos seus artigos. Dessa forma, acredito, consegui resumir, dentro do limite colocado para uma produção deste tipo, as principais idéias, argumentos e reflexões deste autor, pelo menos no que diz respeito mais diretamente ao tema da constituição social da mente e das conseqüências destas idéias para a pesquisa, a Educação e a Psicologia como um todo.

Em síntese, este ensaio tem por objetivo analisar como a mente se torna social, à luz das propostas de Jerome Bruner, destacando os principais temas abordados por este autor e tentando verificá-los também frente às idéias defendidas por Jaan Valsiner. Valsiner é um estudioso que vem obtendo destaque por suas críticas às formas pelas quais a Psicologia vem conduzindo seus estudos, especialmente em Psicologia do Desenvolvimento, idéias congruentes com as do próprio Bruner. Uma análise deste tipo assume um lugar privilegiado na formação e na atuação do psicólogo e da psicóloga, assim como na reflexão do pesquisador e da pesquisadora principalmente em Psicologia, uma vez que leva a uma retomada e reorganização de idéias e argumentos extremamente relevantes, tanto para esta ciência como para este momento histórico.

Desta forma, este artigo suscita ricas discussões em vários “espaços psicológicos” e, de modo especial, naqueles relacionados à Educação, uma vez que a prática educacional é considerada por Bruner como o cenário apropriado para testar a Psicologia Cultural, cuja reformulação tem sido objeto das suas últimas buscas. No contexto escolar, Bruner tem procurado verificar a influência da cultura na aprendizagem escolar ou o papel capacitador desta no desenvolvimento mental, através de indagações como: “o que é preciso para criar uma cultura escolar incentivadora que capacite eficazmente as crianças a utilizar recursos e as oportunidades da cultura mais geral?” (Bruner, 2001, p. xi). Neste sentido, algumas das suas questões relacionam-se à relevância desta psicologia para a educação. Suas pretensões com estes estudos, segundo o autor, resumem-se a fornecer ao menos indícios promissores para encorajar esforços realmente sérios.

Portanto, algumas das discussões de Bruner referem-se diretamente às relações entre a Psicologia Cultural e a Educação. O autor levanta detalhadamente, por exemplo, alguns preceitos, mutuamente relacionados, que deveriam orientar a abordagem psicocultural à educação e que enfatizam os poderes da consciência, da atividade de reflexão, da 
amplitude de diálogo e da negociação no contexto educacional. Preceitos que falam da necessidade de "equipar as mentes com habilidades para compreender, sentir e agir no mundo cultural ...” (Bruner, 2001, p. 46).

Levantar aspectos relacionados à construção de conhecimentos do ser humano e suscitar discussões especialmente no aspecto social da mente têm se apresentado como necessidades sistematicamente observadas, principalmente no contexto escolar (Correia, 1997; Correia \& Campos, 2000; Correia, Lima, \& Araújo, 2001; Correia, Lima, \& Campos, 1999; Correia, Oliveira, \& Andrade, 1998; Falcão, Correia, \& Meira, 2001), embora requisitadas também em outros contextos, os quais a Psicologia, bem ou mal, tem freqüentado. Neste sentido, pretendo fornecer uma pequena contribuição a uma discussão que, apesar do tempo, parece apenas ter iniciado.

\section{Que ciência deveria estudar a mente?}

Bruner é mais um dos autores que chamam a atenção para a fragmentação em que a Psicologia se encontra. Esta fragmentação é ainda seqüela de uma Psicologia que considerava o homem sem mente, ou seja, uma Psicologia positivista cujo objeto de estudo deveria ser diretamente observável ou distante de toda e qualquer questão que envolvesse subjetividade; representada principalmente pela psicologia americana. Esta ciência, então, naturalmente entrelaçada à Antropologia, à Lingüística e à Filosofia pelo seu objeto de estudo, isolou-se e, conseqüentemente, originou dificuldades de diálogo com disciplinas afins, especialmente por ter seguido caminhos metodológicos divergentes. Estas disciplinas, ao contrário da Psicologia, aderiram a uma abordagem mais interpretativa e interessada na produção de significados. Este isolamento trouxe várias dificuldades, entre outras a de não conseguir apresentar grandes achados ou um corpus coerente de conhecimentos.

Dessa maneira, o primeiro movimento revolucionário na Psicologia Cognitiva gritava contra essa “objetividade” e distanciamento do seu verdadeiro objeto, reivindicando um foco para as atividades simbólicas dos seres humanos. Este primeiro movimento, entretanto, enveredou por caminhos não programados por seus idealistas, levando a outro tipo de frieza e distanciamento das questões relevantes da Psicologia - a correlação da mente humana ao funcionamento das “máquinas inteligentes”. Assim “... a ênfase começou a mudar do ‘significado’ para a ‘informação', da ‘construção' do significado para o ‘processamento’ de informações”. (Bruner, 1997a, p. 17). A informação, no entanto, não leva em consideração o significado, pelo contrário, o ignora. Neste sentido, o principal ponto reivindicado pela revolução se perdeu e até os empiricistas aderiram ao movimento, especialmente porque não havia implicado naqueles caminhos nada como mente.

De acordo com Bruner (2001), então, dentro do contexto revolucionário, tínhamos duas visões divergentes de como a mente funciona. A primeira seria um funcionamento semelhante ao mecanismo computacional - "visão computacional” - no qual o problema estava em tratar o conhecimento como formador de informações finitas, codificadas e não ambíguas. Isto contrasta com o processo de saber, uma vez que este é freqüentemente confuso e repleto de ambigüidades. Na segunda visão, a mente seria constituída pelo uso da cultura humana e realizada nela - "culturalismo" - caso em que a mente seria representada pelo simbolismo compartilhado que organiza e interpreta a vida. A primeira procura regras específicas (modelos universais) de processamento, mas estes não dão conta da produção de significados que além de confusos e ambíguos são influenciados pelo contexto. É essa pré-fixação que caracteriza sua maior limitação. A segunda é interpretativa e reconhece aquelas características da produção de significados. Segundo Bruner (2001), o confronto, pode ser colocado em termos de processamento de informações do computacionalismo versus produção de significados do culturalismo.

Assim, não demorou muito e as mesmas questões que levaram à primeira revolução ressurgiram, uma vez que o novo caminho não foi capaz de respondê-las. Em outras palavras, as questões verdadeiramente psicológicas, relacionadas à "caixa preta" e que implicavam em mente ou subjetividade, permaneciam fora do cenário que se dizia da Psicologia. Iniciou-se, então, um novo movimento revolucionário, mais forte, mais claro e mais consciente, embora também mais lento. Nesta segunda revolução, Bruner está tão presente e atuante quanto na primeira. Este autor afirma que tal revolução ainda está acontecendo e chama-se transacionalismo, no sentido de mente situada, compartilhada, em transação ou negociação, e como sinônimo também de contextualismo, contra o objetivismo ilusório.

A revolução cognitiva, como afirma Bruner, objetiva (uma vez que ainda está em curso) trazer a mente, que havia se tornado tabu, de volta às ciências humanas após um longo inverno de objetivismo. Neste sentido, o autor critica o positivismo e todos os "ismos" que atrofiaram nossas pesquisas, especialmente o persistente antimentalismo, ou a chamada "Psicologia Cientifica", cuja rigorosidade ou limitações impediram de se estudar temas importantes para a Psicologia.

Bruner, assim como Valsiner (2000), critica a direção que os estudos em Psicologia Cognitiva, e mais especificamente em Psicologia do Desenvolvimento, tem seguido e vem se mantendo, em relação às ferramentas utilizadas para medir o fenômeno e à consideração da metodologia como "mercados epistêmicos” e “igrejinhas” metodológicas. Em outras palavras, uma “miopia empiricista” (Valsiner, 2000), vislumbrada em "pequenos estudos limpos e [na] metodolatria” (Allport, citado por Bruner, 1997a). Outrossim, uma abordagem mais interpretativa não significa a dispensa total das investigações em laboratórios, tampouco da busca por universais; o teor da questão a ser respondida deveria ser o indicador do método a ser usado e não o contrário. Nestes aspectos encontram-se alguns dos pontos comuns entre Bruner e Valsiner.

Uma das principais questões daquela segunda revolução, como afirma Bruner (1997a), é entender a mente como criadora de significados, buscando compreender a interação na qual a 
mente constitui e é constituída pela cultura e a construção de significado mediando esta interação entre mente e cultura. Vygotsky, ainda segundo esse autor, teria sido um dos poucos a ver este papel constitutivo da cultura. Dessa forma, uma psicologia individual, no sentido de organismo, torna-se inadequada e irrelevante. Bruner (1997a) propõe uma psicologia com orientação cultural, interessada na ação, especialmente no caráter situacional da ação, para alcançar seu objeto de estudo. O que os sujeitos dizem, fazem e todo o contexto em volta seria o ponto de investigação, no singular por ser considerado um processo e com tais partes indissociáveis, sem com isso estar falando num relativismo extremo, como os críticos geralmente levam-nos a pensar.

Dessa forma, qual seria o caminho que conduziria à superação dessas limitações construídas ao longo do tempo e que atingiria essa produção de significados? Bruner propõe uma Psicologia Cultural, cujo principal instrumento seria a Psicologia Popular (Folk Psychology); chamada por Bronckart (1998) de "mundo real"; pois ela leva em consideração as intenções, desejos e crenças dos personagens, além do contexto onde estas nascem. A Psicologia Cultural focalizaria o previsível e usual na condição humana. A Psicologia Popular seria uma característica dessa e um importante instrumento da própria cultura. A Psicologia Popular constitui os significados institucionalizados e relacionados às ações humanas, aos mundos, e eles orientam e até dirigem os atos de cada um de nós; e nem sempre os significados são os mesmos para cada indivíduo. A essência do indivíduo (o si-mesmo) também nasce das interações sociais, do respeito, digamos assim, às psicologias populares. Esta Psicologia fala sobre como nossas mentes funcionam, sobre como devemos nos comportar, estilos de vida, compromissos em relação a eles, entre vários outros aspectos.

\section{A Psicologia Cultural}

Bruner (1997a) tenta esclarecer o que é a Psicologia Cultural através de uma complexa questão que ele chama de questão do si-mesmo (self); uma questão posta de lado por ser considerada demasiado subjetiva. Existiriam várias indagações a respeito do si-mesmo: o que envolveria a sua constituição - se família e posses; se a transação com o Outro generalizado, através do diálogo; se seria conceitual; real ou ideal ou ainda se seria uma forma de estruturar nossa consciência e nossa identidade.

Parece-me que uma Psicologia Cultural impõe duas exigências intimamente relacionadas com o estudo do si-mesmo. Uma delas é que tais estudos devem focalizar os significados em cujos termos o si-mesmo é definido tanto pelo indivíduo como pela cultura na qual ele participa. (...) A segunda exigência, então, está em sintonia com as práticas nas quais os significados do si-mesmo são atingidos e colocados em uso. Esta, com efeito, nos oferece uma visão mais distribuída do si-mesmo. (Bruner, 1997a, p. 101)

A Psicologia Cultural deve explorar, além dos significados, o uso destes na prática - em ação. Ela vai ser interpretativa e vai estar interessada nas formas através das quais os seres humanos produzem significados nos contextos culturais onde estão inseridos. As pessoas são resultado deste processo de produção de significados, no qual a educação está intimamente relacionada como contexto cultural situado e no sentido de que a "cultura molda [educa] a mente" (Bruner, 2001, p. viii).

O contexto social, assim, está envolvido na construção do nosso conhecimento. Não existe conhecimento isolado no indivíduo, ele está espalhado entre as anotações, grifos, livros, formas de consulta, amigos e tudo o mais que constitui quase uma infinidade de lugares - o conhecimento é distribuído; formas de justificativas e explicações que usamos são “... cada qual talhada e 'armada' (scaffolded) pelas circunstâncias de seu uso” (Bruner, 1997a, p. 94). Tudo isso atesta a natureza cultural do conhecimento e da sua aquisição. E assim o é o si-mesmo, situado cultural e historicamente. O sentido do si-mesmo, como o da mente, é um caminho com duas vias em relação à cultura, ou seja, procede de dentro para fora e também no sentido inverso.

Enfatizar a Psicologia Popular de uma cultura como moldadora do comportamento humano não seria negar nossa constituição biológica, mas esta sozinha nos oferece apenas um conhecimento parcial sobre o comportamento, especialmente porque é a cultura que nos diferencia, distingue ou fornece qualidades diferenciais de todas as outras espécies (Donald, 2000; Tomasello, 1999).

Bruner (2001) irá além em suas fundamentações, no sentido de remeter seus argumentos até ao nosso sistema nervoso central, demonstrando que ele parece ter evoluído de tal modo que reage diferentemente, por exemplo, àquelas versões esperadas e inesperadas do mundo (as que violam, ou não, o modelo de mundo registrado nele):

... o fenômeno complexo que tão irrefletidamente chamamos de "cultura" parece impor restrições sobre como a mente funciona e até mesmo sobre os tipos de problemas que somos capazes de resolver. Mesmo um processo psicológico tão primário quanto a generalização (...) é regulado por interpretações do significado culturalmente apoiadas, e não pelo acionamento de um sistema nervoso individual. (p. 157)

Buscar subsídios na neurologia ou psiconeurologia para fundamentar sua tese da mente social é uma característica encontrada também na produção de outros autores. Os estudiosos convergem na tentativa de defender o papel central da cultura na evolução cognitiva que podemos observar ao longo da história. E o fazem contra-argumentando as teorias que consideram esta evolução da mente como isolada ou autônoma. Donald (2000), que cita Bruner como o maior divulgador das idéias socioculturais, apresenta resultados de estudos neurológicos e estudos com animais que o levam a afirmar que a nossa mente pode ser tão influenciada pela esmagadora cultura simbólica, durante o desenvolvimento, de forma a poder remodelar a estrutura operacional (o modo como funciona) do sistema cognitivo. Para Donald, a cultura forma e estrutura a mente, no sentido de determinar a natureza das habilidades operacionais de uma criança. Existiria, assim, uma verdadeira simbiose entre cérebro 
e cultura e ela seria a única variável que pode ter um impacto qualitativo na estrutura que compõe a cognição (ao contrário da variável nutrição, por exemplo). A cultura, fazendo uma analogia, é que configura o complexo sistema simbólico necessário, ou seja, é ela que traduz e ao mesmo tempo monta o "programa".

Neste sentido, esse autor não nega a existência de universais cognitivos e culturais, mas afirma que eles descrevem de forma incompleta a arquitetura do cérebro. Afirma ainda que nem ele, nem ninguém, fala da determinação da cultura na visão, por exemplo, mas que isso é inegável em relação à arquitetura funcional do letramento e linguagem, cuja programação é totalmente cultural.

Bruner (1986) também enfatiza o papel da linguagem no desenvolvimento humano, colocando-a como uma ferramenta essencial no processamento do mundo, no planejamento e na ação humana, assim como na "modernização" da mente através da história e da cultura. Este autor concorda com “.... a visão de que o homem estava sujeito ao jogo dialético entre a natureza e a história, entre suas qualidades como criatura da biologia e como um produto da cultura humana” (p. 76).

Dessa forma, não podemos compreender o ser humano e sua ação sem conhecer tanto a cultura como a biologia, e não podemos entender a ação humana sem considerar o seu caráter situacional. A cultura, então, não pode ser vista simplesmente como algo acrescentado à mente natural, pois aquela é constitutiva desta. A cultura cria uma rede de expectativas mútuas entre os humanos, uma espécie de sintonia que não é vista em nenhuma outra espécie. Para o autor, a Psicologia deve, neste sentido, mesclar os insights biológicos, evolutivos, psicológicos individuais e culturais para compreender o funcionamento mental humano. E tudo isso é vital para uma Psicologia que ele chama de cultural. Em síntese, sem negar a biologia e os recursos físicos, a Psicologia Cultural quer demonstrar como as mentes "são reflexos da cultura e da história”. Nenhum dado, portanto pode ser interpretado à revelia da cultura humana. E a forma de ter acesso e interpretar os dados provenientes da Psicologia Popular, que forneceriam subsídios à Psicologia Cultural, seria através da narrativa. Esta, segundo Bruner (1997a), seria o princípio organizador da experiência humana, ou seja, desta Psicologia Popular.

\section{Narrativa: fonte de dados para o estudo da mente}

Bruner (1986) coloca a narrativa como a moeda comum entre nosso self e o mundo social; o que indica, certamente, uma mesma origem. Explorar a natureza da narrativa, desde que sejamos sensíveis ao contexto em que foi revelada, seria explorar um modo de raciocínio. As suas diferentes formas teriam origem na cultura, e assim, a narrativa apresentar-se-ia como uma fonte de dados valiosa para o estudo da mente.

Neste sentido, existem questões importantes em relação à narrativa que precisam ser melhor investigadas, como o que é, em que se diferencia das outras formas de discurso e de outros modos de organizar a experiência e a que funções ela serve (Bruner, 1997a). A narrativa possui características que a colocam em um lugar relevante na investigação da mente, tais como seqüencialidade de eventos e envolvimento de estados mentais. Segundo Bruner (2001), existiriam nas realidades narrativas alguns universais, os quais podem ser resumidos da seguinte forma: a) as narrativas possuem uma estrutura do tempo que não é medida por relógios, mas pelos eventos ou ações humanas mais importantes; b) é fácil avançar ou voltar no tempo quando se trata da narrativa; c) as ações têm motivos, implicam estados intencionais, crenças, desejos, valores, não são determinadas por causa e efeito; d) não possuem uma única interpretação, e sempre existe a possibilidade de questionamento, independente do quanto sejam verificadas; e) muitas vezes a sua referência aponta ou expressa um sentido para narrativa que não é direto; f) existe espaço para uma certa contestação, para se contar e negociar versões da história; g) tem de romper com o canônico para valer ser contada.

As características da narrativa são mantidas independentemente de serem reais ou imaginárias, e estas levantam, de acordo com Bruner (1997a), a questão sobre a sua origem, ou seja, uma vez que ela está sempre presente, o autor questiona se não teríamos uma aptidão ou predisposição para organizar nossa experiência através dela.

Assim, considerando as características e a importância da narrativa, afirma que nossos dados de pesquisa poderiam ser autobiografias espontâneas, uma versão longitudinal do si-mesmo; característica universal das narrativas, além de serem, ao mesmo tempo, expressões de forças sociais e históricas. As pessoas transformam suas experiências no mundo em narrativas, então isso não poderia ser negligenciado nas pesquisas em Psicologia Cognitiva. O fato, de acordo com Bruner (2001), é que vivemos a maior parte das nossas vidas em um mundo que é construído e que obedece às regras e aos recursos da narrativa.

$\mathrm{O}$ pensamento narrativo, tanto quanto o pensamento lógico-científico, parece sempre presente no ser humano, suas formas variam de acordo com a ênfase dada pela cultura, embora sejam universais. Segundo Bruner (1986), mesmo que se tenha um vasto conhecimento nos procedimentos do segundo, isso não garante muito sobre o como fazer uma boa história. Mas as histórias são importantes para aqueles que investigam a mente humana, pois elas não são independentes do que ocorre nas mentes de quem participa delas: “... provavelmente são a matéria da vida daqueles cujo comportamento eles [os psicólogos] estudam” (p. 45). Por isso, estes dois pensamentos vivem lado a lado, uma vez que através da narrativa podemos construir a realidade psicológica e cultural que permeia a história real dos participantes; então como negligenciar qualquer um deles?

Ao contrário do que foi valorizado outrora e a despeito do que foi desvalorizado, deveríamos estar interessados no que as pessoas dizem sobre o que elas e os outros fazem e nos motivos que estão por trás das suas ações, além do interesse sobre o que elas realmente fazem. Dizer e fazer para uma Psicologia Cultural é unidade de análise, portanto, são inseparáveis. A ação e, especialmente, a ação situada é o ponto mais importante para uma Psicologia Cultural. A mente, segundo Bruner (2001), é proativa - orientada para os 
problemas - intencional e construcional; o sujeito, portanto, é autor. Neste sentido, o que está na mente não é simplesmente aquilo que foi captado pelos sentidos, muito menos pelos instrumentos que extraíram os dados. Ela busca o diálogo com outras mentes também ativas, na conversação, na colaboração. Então, “aprender termos como pensar, acreditar, prestar atenção, lembrar é, portanto, aprender uma teoria da mente" (p. 107). E isso traz implicações e pontos para reflexões fundamentais, tanto para a pesquisa como para a escola.

Bruner (1986) vai distinguir aqueles pensamentos (narrativo e lógico-científico) como ciências humanas (“... apreciadas como invenções engenhosas das mentes humanas, como criações produzidas pelos diferentes usos da mente”, p. 47) e ciências, respectivamente, colocando a necessidade de interpretar a primeira, pois ali se encontram os significados provenientes da mente humana e objeto de estudo da segunda. O levantamento de hipóteses na primeira cria possibilidades e necessidades de conhecimento para a segunda e isso em nada desvalorizaria a Psicologia, pois a necessidade de interpretar não extingue a priori o empírico, experimental ou quantitativo. Simplesmente mostra a interrelação entre interpretar e explicar. Isso precisa ficar cada vez mais claro para possibilitar a destituição de mitos, deturpações, preconceitos ou visões estreitas.

A narrativa, de acordo com Bruner (1986, 1997a), estaria interpretando a vida em ação e seria, dessa forma, uma das principais ferramentas da Psicologia Popular ou da ciência humana popular, de onde deveriam sair as informações e investigações da Psicologia Cultural. A narrativa lida com o material da ação e da intencionalidade humanas; ela tem relação com o significado dado às coisas pelo seu autor e envolve a negociação de significados entre os seres humanos.

\section{$O$ self transacional}

Nas ciências humanas, ainda segundo Bruner (1986), encontra-se o que esse autor chama de self transacional. O self transacional é um self em negociação com os outros sociais e com a cultura, ou seja, em negociação com o mundo social circundante: “... acredito que construímos ou constituímos o mundo, acredito também que o self é uma construção, um resultado de ação e simbolização” (p. 136).

O termo self transacional e o interesse por ele aparentemente vêm da importância das transações para os relacionamentos humanos, para a construção do si-mesmo e, especialmente, para o uso da linguagem. Com transações, Bruner (1986) tem em mente “as negociações que são estabelecidas numa mútua partilha de pressupostos e convicções sobre como o mundo é, como a mente funciona, sobre o que vamos fazer e como a comunicação deveria acontecer” (p. 61). O termo self transacional também tem a ver com o fato de que geralmente temos algum acesso às mentes dos outros, no sentido de que o que os outros fazem ou dizem, além de dever fazer algum sentido é mais ou menos presumível. ${ }^{2}$ A organização de nossas ações ou a percepção da mente do outro são, de certa forma, reguladas por estas presunções.
Bruner (1986), discutindo Vygotsky, por exemplo, chama a atenção para o que acontece, do seu ponto de vista, quando atuamos na zona de desenvolvimento proximal. Na intervenção de um mais velho ou mais capaz está demonstrada a nossa capacidade de "entrarmos" na mente daqueles que estão à nossa volta. O mais velho faria um "empréstimo" de consciência, dentro de uma transação negociável. Entretanto, isso não é possível em qualquer situação, com qualquer pessoa ou em qualquer tempo; entra aqui a questão do situado, do compartilhado; o contexto além de todos esses é que fornece suporte para a decodificação do mundo.

Neste sentido, referir-se a algo com a intenção de atrair a atenção de outro para esse algo, requer, mesmo em sua forma mais simples, alguma forma de negociação, algum processo hermenêutico. E isto se acentua quando a referência não está presente ou acessível à demonstração ou a outra manobra ostensiva. (p. 67)

Como abordado anteriormente, Bruner (1986) não descarta o auxílio biológico nisto tudo, como às vezes pode parecer. Em contrapartida, o acha insignificante para o resultado final que encontramos nos seres humanos, por isso não aceita o biológico como sendo o responsável ou mesmo o fator que possa explicar todo o fenômeno. Outrossim, haveria uma base organizada sistematicamente sobre a qual a referência lingüística se apóia e esta base seria natural da mente e não simplesmente aprendida, embora a transformemos com a experiência vivenciada. Dito de outra forma, nasceríamos equipados com meios que possibilitariam essa "leitura" da mente dos outros assim como do mundo em geral, mas “... a cultura e a busca por significado são a mão modeladora, a biologia é a restrição e (...) cabe à cultura [assim também à educação] deter o poder de afrouxar essas limitações” (p. 30).

Dessa maneira, conheceríamos outras mentes e seus mundos. Nas relações entre as palavras e as expressões, em conjunto com as referências sutis do mundo, constituir-se-ia a esfera do significado, na qual até o não dito exerce influência: "na maioria dos casos de diálogo, o silêncio é interpretável, tem um significado” (Bruner, 1986, p. 89). Uma psicologia preocupada com os significados, ou com a mente criadora de significados, é uma psicologia que se torna cultural.

\section{A construção de significados}

As questões relacionadas a como os seres humanos produzem significados foram as que intrigaram os psicólogos que iniciaram a primeira revolução cognitiva (Bruner, Goldnow, \& Austin, 1956). Tais psicólogos reivindicavam respostas às várias questões que a tão valorizada objetividade não conseguia responder; uma delas era “... como o significado do texto se transforma em um significado na cabeça de um leitor”. (Bruner, 1986, p. 159). Para Bruner, negociar e renegociar significados seria a grande conquista do ser humano, e o ponto mais relevante para a investigação do significado seria “... a natureza e a modelagem cultural da produção de significado e o lugar central que ela ocupa na ação humana” (Bruner, 1997a, p. xi). Estudar o significado, porém, não é uma empreitada fácil, pois muitas vezes ele é ambíguo e indeterminado. 
Bruner (1986) afirma que sem a extração de significado não poderia haver linguagem, mito, arte ou mesmo cultura, pois esta seria um fenômeno imbricado tanto na produção como nas negociações de significados: “... aprender a usar a linguagem envolve ao mesmo tempo aprender a cultura e aprender como expressar as intenções em congruência com a cultura” (p. 69). A criança, por exemplo, desde muito pequena, procura superar tal ambigüidade, dar sentido às coisas que acontecem à sua volta, inclusive em seus monólogos, quando tenta interpretar os acontecimentos vividos em suas interações com os outros.

Assim, os processos de linguagem e os processos mentais estão relacionados e os psicólogos e as psicólogas precisam conhecer a linguagem para poderem explorar os processos mentais. Bruner usa o termo realidade psicológica das estruturas lingüísticas para externar essa relação. Para ele, a questão é como processos psicológicos produzem construções de mundo e o que podemos dizer psicologicamente sobre realidades psicológicas.

Segundo Bruner (1997a), nós demoramos muito a perceber a importância da linguagem para a natureza humana; Vygotsky teria sido uma das poucas exceções. E sendo a linguagem um dos principais instrumentos culturais, então nós demoramos muito também para perceber o significado da cultura para o funcionamento humano. A cultura seria, neste sentido, o kit de ferramentas que precisávamos utilizar para nos adaptarmos ao mundo (cultural), ampliando ou redefinindo nossas capacidades de funcionamento: “... nem a mente sozinha nem a mão sozinha podem realizar muito sem os auxílios e as ferramentas que as aperfeiçoam" (Francis Bacon, citado por Bruner, 1997a, p. 128). A linguagem seria um desses principais auxílios ou instrumentos.

O significado dos conceitos sociais está no mundo, na negociação entre as pessoas; a própria cultura, que é um produto do uso da linguagem, precisa ser interpretada por quem participa dela. E a cultura é, ao mesmo tempo, um processo que está em constante recriação, através das interpretações e negociações dos seus participantes. Assim, a linguagem não tem a função apenas de transmitir, ela cria realidades e consciência, fornece novos meios à cognição para investigar e explicar o mundo. A interpretação, a invenção e a revisão dos sistemas de símbolos estariam por trás de muito dos nossos conhecimentos, ações, artes, ciências, do nosso mundo em geral, ou seja, os significados de tais sistemas dependem da cultura, ainda que possam usar os mesmos símbolos. Segundo Bruner (2001), "embora os significados estejam 'na mente', eles têm suas origens e sua importância na cultura na qual são criados. É esta localização cultural dos significados que garante sua negociabilidade e, no final das contas, sua comunicabilidade" (p. 16).

Pois bem, o interpretativismo, outro nome dado à segunda revolução cognitiva e designação - segundo Bruner (1997a) - inspirada em Mead, procura interpretar os fenômenos cognitivos sempre à luz da cultura humana e dirigida à produção de significados. O significado é dado de forma narrativa e a partir de um pano de fundo que seria as normas ditadas socialmente. Neste sentido, interpretamos os eventos "narrativamente", à medida que negociamos e renegociamos significados na prática social, caracterizando-os como conquistas sociais. Logo após o nascimento, a criança começa a construir significados, de maneira que antes da linguagem já existem intenções comunicativas bem estruturadas, como apontar ou enganar, embora essa construção seja significativamente enriquecida com a aquisição da linguagem.

Mas essa linguagem também vai nascer e se estruturar em meio ao social, uma vez que a criança aprende também o que, quando, onde e para quem falar o quê; sua aquisição, portanto, é sensível ao contexto. Este precisa ser, digamos, significado para poder auxiliar na própria aquisição da linguagem. Em outras palavras, teríamos aptidões prélingüísticas para o significado. Bruner (2001) ainda afirma que "por mais que o indivíduo pareça operar por conta própria ao realizar sua busca de significados, ninguém pode fazê-lo sem o auxílio dos sistemas simbólicos da cultura” (p. 16). Portanto, sendo tudo isso social e admitindo-se o papel fundante da linguagem para o pensamento, a mente se torna social.

\section{Considerações Finais}

A década de noventa do século XX, segundo Valsiner e Van der Veer (2000), marca uma época de retorno ao pensamento da constituição social da mente. Atualmente existe um grupo, com cada vez mais adeptos, daqueles que defendem este pensamento. A análise das principais idéias de Bruner, assim como da sua "militância" e extensa produção nesta direção, identifica-o como um componente representativo neste grupo. As concepções ali geradas, no entanto, não são coesas como poderia parecer, pois algumas questões são respondidas através de diferentes focos, como aquela relacionada à magnitude da influência deste social. Um desses focos dirige-se à interdependência, interinfluência ou co-construção entre o individual e o social, no qual Bruner seria identificado (Valsiner, 2000, p. 398).

Valsiner (2000) e Valsiner e Van der Veer (2000), nesse sentido, chamam a atenção para algumas características que não poderiam ser negligenciadas no design metodológico dos estudos sobre o desenvolvimento e a mente humana, como o fato de ser este um sistema dinâmico, aberto e em construção. Há ainda a questão da irreversibilidade do tempo, no sentido da impossibilidade de repetição de alguns fenômenos. Estas idéias são enfatizadas de outras formas também por Bruner, argumentando, inclusive, que considerar tais características significa enfrentar o "velho" reducionismo. (Bruner, 1997b). A ênfase deste autor no estudo da ação humana, por exemplo, depõe a seu favor no que concerne à atenção às características do fenômeno como um sistema em construção. Essa ação, para Bruner, é definida pelos sistemas simbólicos, profundamente arraigados na cultura e na língua, acessíveis através da participação com os outros em atividades culturalmente organizadas - como a educação escolar. 
Para captar este dinamismo do fenômeno estudado, Bruner sugere uma Psicologia interpretativa, que busque "as regras que os seres humanos aplicam para a produção de significado em contextos culturais” (Bruner, 1997a, p. 102). Advoga, assim, a necessidade de não rejeitarmos as formas de realidade narradas por nossos sujeitos de pesquisa, uma vez que isso seria tão restritivo quanto à tão criticada rigorosidade empiricista. Por fim, sugere que a Psicologia deve atentar tanto para o biológico e para o cultural, como para o modo sutil em que estes interagem numa situação local. O autor reivindica uma Psicologia cujos métodos sejam biosócio-situacionais (p. 158).

Em síntese, pode-se afirmar que todas aquelas características são coerentes com a proposta de Bruner de uma psicologia interpretativa, interessada na produção e uso de significados em contextos culturais nos quais os indivíduos estão inseridos. Ou seja, uma psicologia interessada no que as pessoas dizem sobre o que elas e os outros fazem. Desta maneira, os pesquisadores tentam alcançar o que é subjetivo e privado da mente, mas que gera uma produção pública (Bruner, 1997b). É nesse processo interpretativo que se torna observável o fazendo sentido através dos sistemas simbólicos, cujo principal veículo é a construção de narrativas que dependem tanto de operações cognitivas como de cânones culturais. (Feldaman, Bruner, Kalmar \& Renderer, 1994).

As idéias de Valsiner, assim como as de Bruner, sobre como os estudos da mente devem ser efetivados, em conseqüência daquelas características, são possíveis e extremamente relevantes, mas são, sobretudo, muito difíceis de realização. É necessário, portanto, bastante cautela, para não perder a cientificidade e para não relevar o aprofundamento teórico, de maneira que se possa obter de fato resultados significativos.

Isso é o que há muito está sendo reivindicado e que nos aproxima dos verdadeiros objetos da Psicologia, geralmente não identificados com a rigorosa idéia de objetividade, ainda tão valorizada nos meios acadêmicos. A principal pergunta o que se está procurando responder - geralmente não está posta nas críticas e discussões, embora ela seja a única (pelo menos deveria ser) que tem autoridade para guiar a escolha do método a ser utilizado.

Parece claro que todas as discussões resgatadas aqui têm influência também, direta ou indireta, e portanto são relevantes, para a educação escolar. Bruner traz, subjacentes às questões levantadas, importantes pontos para a reflexão daquelas mais diretamente relacionadas à Educação, como a importância da ação, da participação em atividades compartilhadas e da conseqüente e necessária negociação de significados para um sistema em construção. Pontos, entretanto, distantes do panorama freqüentemente observado nos contextos de salas-de-aula, que ainda se assemelham mais à concepção computacional, na qual a "aquisição" de conhecimentos é tratada como composta de informações finitas, claras e previamente codificadas. Posturas que não favorecem a interação, inclusive entre mente e cultura, caracterizada como matéria-prima da construção do conhecimento.
Por fim, penso que as contribuições - não só dos estudiosos desta última década, na qual enfatizo a participação e contribuição de Bruner, como daqueles que iniciaram ou propiciaram essa discussão há muitas décadas - ainda vêm sendo retomadas e, por isso, continuam constituindo uma esperança para o avanço de nossa compreensão a respeito da constituição social da mente humana ou, pelo menos, para mais um alerta sobre a rota a ser tomada. Mas, infelizmente, continuo concordando com as contundentes críticas tanto de Valsiner como de Bruner sobre as poucas mudanças verificadas no panorama geral dos estudos da cognição humana. Especialmente, sobre a permanência de questões centrais ou a ausência de respostas a tais questões. Lamento também a significativa distância entre algumas das parcas (mais relevantes) contribuições, geradas neste conturbado cenário, e a Educação. Uma aproximação neste sentido, certamente, favoreceria a elevação dos dramáticos índices de qualidade e o abaixamento dos índices de fracasso sistematicamente verificados no contexto escolar.

\section{Referências}

Bronckart, J. P. (1998). Teorias da ação, da fala, da linguagem natural e do discurso. In J. V. Wertsch, P. del Rio \& L. Alvarez (Orgs.), Estudos socioculturais da mente (pp. 72-88). Porto Alegre: Artmed.

Bruner, J. (1986). Actual minds, possible worlds. Cambridge, Massachusetts: Harvard University Press.

Bruner, J. (1997a). Atos de significação. Porto Alegre: Artes Médicas.

Bruner, J. (1997b). Celebrating divergence: Piaget and Vygotsky. Journal of Human Development, 40, 63-73.

Bruner, J. (2001). A cultura da educação. Porto Alegre: Artmed.

Bruner, J. S., Goodnow, J. J., \& Austin, G. A. (1956). A study of thinking. Nova York: Wiley.

Correia, M. F. B. (1997). Como o psicólogo escolar está atuando na sua função de mediador entre o conhecimento acadêmico e a Educação? [Resumo]. In Sociedade Interamericana de Psicologia (Org.), XXVI Congresso Interamericano de Psicologia. Resumos (p. 240). São Paulo: Autor.

Correia, M. F. B., \& Campos, H. (2000). Psicologia Escolar: histórias, tendências e possibilidades. In O. H. Yamamoto \& A. Cabral Neto (Orgs.), O psicólogo e a escola (pp. 59-97). Natal: EDUFRN.

Correia, M. F. B., Lima, A. P. B., \& Araújo, C. R. (2001). As contribuições da Psicologia Cognitiva e a atuação do psicólogo no contexto escolar. Psicologia: Reflexão e Crítica, 14(3), 553-561.

Correia, M. F. B., Lima, A. P. B., \& Campos, H. (1999). Proposições e dificuldades da atuação do psicólogo no contexto escolar [Resumo]. In Conselho Regional de Psicologia e Universidade Federal da Bahia (Orgs.), I Congresso Norte-Nordeste de Psicologia. Resumos. Salvador: Autor.

Correia, M. F. B., Oliveira, I. C., \& Andrade, K. L. (1998). Conhecimento dos educadores sobre as contribuições da Psicologia para a Educação [Resumo]. In Associação Brasileira de Psicologia Escolar (Org.), IV Congresso Nacional de Psicologia Escolar. Resumos (p. 68). João Pessoa: Autor.

Donald, M. (2000). The central role of culture in cognitive evolution on the myth of the "isolated mind”. In L. P. Nucci \& G. B. Saxe (Orgs.), Culture, thought, and development. Mahwah, New Jersey: Lawrence Erlbaum Associates.

Falcão, J. T. R., Correia, M. F. B., \& Meira, L. R. L. (2001). Construtos teóricos em Psicologia da Aprendizagem e do Desenvolvimento e a Psicologia Escolar: complementaridades, rupturas e perspectivas de 
intervenção [Resumo]. In Sociedade Brasileira de Psicologia (Org.), XXXI Reunião anual de Psicologia - Resumos. Rio de Janeiro: Autor.

Feldaman, C., Bruner, J., Kalmar, D., \& Renderer, B. (1994). Plot, plight, and dramatism: interpretation at three ages. In W. F. Overton \& D. S. Palermo (Orgs.), The nature and ontogenesis of meaning (pp. 255-277). Hillsdale, New Jersey: Lawrence Erlbaum Associates.

Fosnot, C. T. (1998). Construtivismo: uma teoria psicológica da aprendizagem. In C. T. Fosnot (Org.), Construtivismo: teoria, perspectivas e prática pedagógica (pp. 25-50). Porto Alegre: Artmed.

Geertz, C. (1978). The interpretation of cultures. Nova York: Basic Books.

Gould, J. S. (1998). Uma abordagem construtivista do ensino e da aprendizagem em artes da linguagem. In C. T. Fosnot (Org.), Construtivismo: teoria, perspectivas e prática pedagógica (pp. 111-122). Porto Alegre: Artmed.

Rogoff, B. (1998). Observando a atividade sociocultural em três planos: apropriação participatória, participação guiada e aprendizado. In J. V. Wertsch, P. del Rio \& L. Alvarez (Orgs.), Estudos socioculturais da mente (pp. 123-142). Porto Alegre: Artmed.
Santos, J. L. (1996). O que é cultura. São Paulo: Brasiliense.

Tomasello, M. (1999). The cultural origins of human cognition. Cambridge, Massachusetts: Harvard University Press.

Valsiner, J. (2000). Culture and human development: an introduction. London: Sage.

Valsiner, J., \& Van der Veer, R. (2000). The social mind - construction of the idea. Cambridge, Massachusetts: Cambridge University Press.

Vasconcellos, V. M. R., \& Valsiner, J. (1995). Perspectiva co-construtivista na Psicologia e na Educação. Porto Alegre: Artes Médicas.

Wertsch, J. V. (1998). A necessidade da ação na pesquisa sociocultural. In J. V. Wertsch, P. del Rio \& L. Alvarez (Orgs.), Estudos socioculturais da mente (pp. 56-71). Porto Alegre: Artmed.

Wertsch, J. V., Del Río, P., \& Alvarez, L. (1998). Estudos socioculturais: história, ação e mediação. In J. V. Wertsch, P. Del Rio \& L. Alvarez (Orgs.), Estudos socioculturais da mente (pp. 11-40). Porto Alegre: Artmed.

Nota

1. A questão da nossa auto-percepção e do reconhecimento do outro como agentes intencionais, já nos primeiros anos de vida, característica especificamente humana, é detalhadamente discutida por Tomasello (1999).

Mônica F. B. Correia, mestre e doutoranda em Psicologia Cognitiva, Universidade Federal de Pernambuco, é professora no Departamento de Psicologia da Universidade Federal da Paraíba. Endereço para correspondência: Av. Abdias Gomes de Almeida, 997 - Tambauzinho; João Pessoa/PB - CEP 58042-100. Tel.: (83) 224-1642. Fax: (83) 216-7064/7006. E-mail: moncorreia@uol.com.br 